
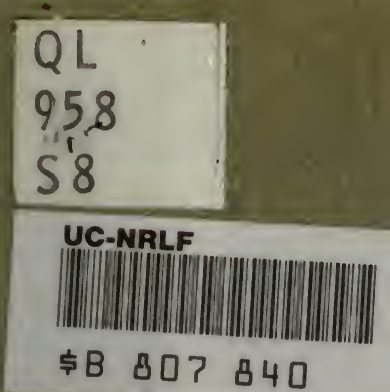

\title{
STUDIES ON THE GERM CELLS OF APHIDS
}

BY N. M. STEVENS

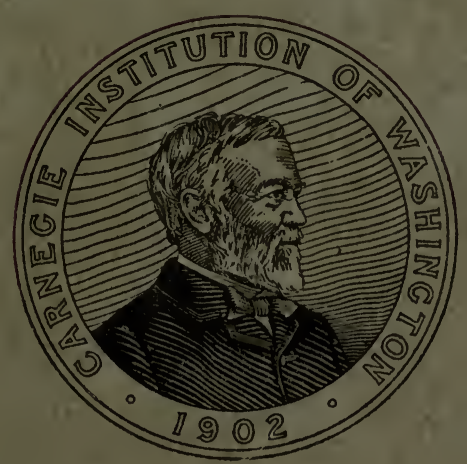

WASHINGTON, D. C.

Published by the Carnegie Institution of Washington May, 1906 


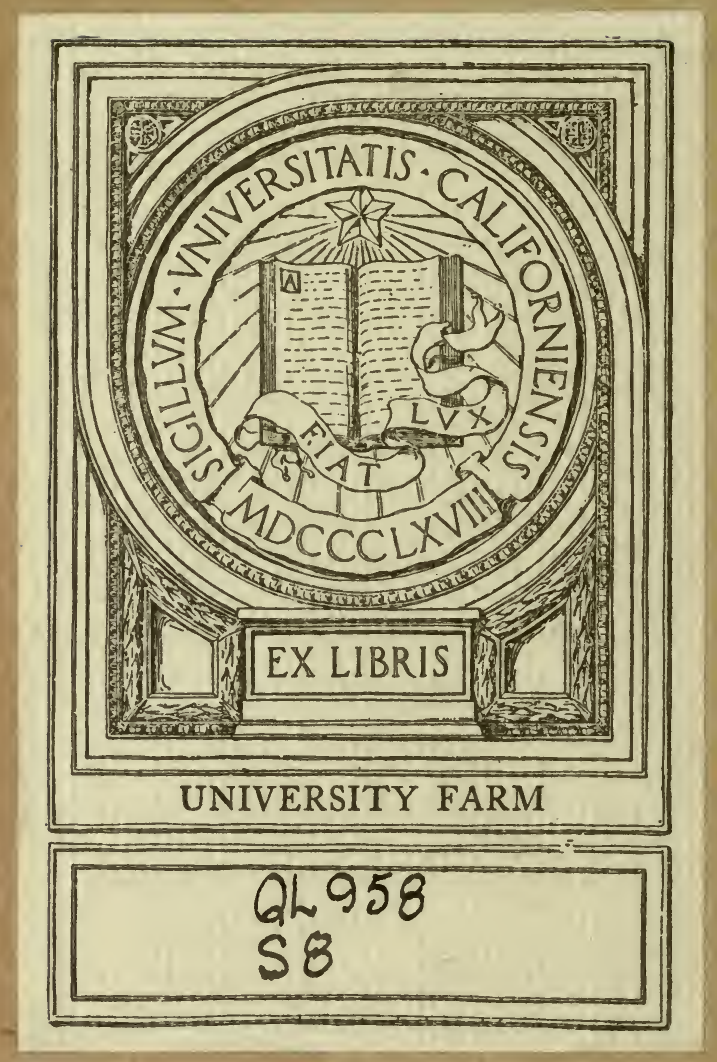






\title{
STUDIES ON THE GERM CELLS OF APHIDS
}

\author{
BY N. M. STEVENS
}

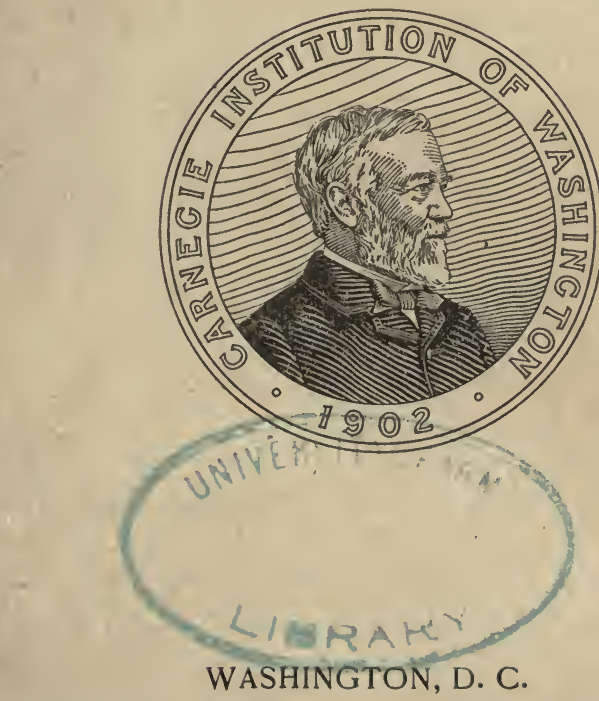

Published by the Carnegie Institution of Washington May, 1906

\section{LIBRARY}




\section{CARNEGIE INSTITUTION OF WASHINGTON}

Publication NO. $5 \mathrm{I}$. 


\title{
STUDIES ON THE GERIM CELLS OF APHIDS.
}

\author{
By N. M. STEVENS.
}

\section{INTRODUCTION.}

My previous report on the germ cells of aphids was based on a study of the parthenogenetic and winter eggs of Aphis rosae, the brown rose aphid, and of the spermatogenesis of Aphis oenotherae, found on the inflorescence of Oenothera biennis.

During the past summer and autumn material from more than twenty species has been collected and examined. In some cases it has been possible to study all of the forms of one species, in other cases only the parthenogenetic eggs, only the winter eggs, or only the spermatogenesis.

It has become evident in the course of the work that little dependence is to be placed on the present classification of aphids, and that a reclassification based on the cytology of the germ cells may be necessary. For example, it appears that at least three distinct species are usually included under the name Aphis rosae. No attempt will, therefore, be made in this paper to give the Latin names of the species studied, but they will be designated by the names of their host plants, and identified by brief description where it seems necessary.

This comparative study was undertaken in the hope of throwing more light on the question of sex determination, and the descriptive part of the paper will be followed by a further discussion of the bearing of the facts recorded on that problem.

\section{METHODS.}

The methods used were for the most part the same as in the previous work-fixation with Gilson's "acetic alcohol with sublimate" (Lee, sixth edition, p. 65) and staining by Heidenhain's iron-hæmatoxylin method. Some material was fixed in Flemming's fluid, Hermaun's platino aceto-osmic, and Gilson's mercuro-nitric, but such fixation brought out no new points in structure, and was, in general, less satisfactory than fixation with Gilson's acetic alcohol-sublimate formula. The latter fluid was used at first on account of its great 
penetrating power, and because aphids will not sink in any water mixture; but by opening the insects with needles in the fluid any method of fixation may be used.

Material from different species, though fixed in the same way, takes the stain so differently that it has often been found necessary to restain several times to get just the right differentiation for counting and drawing the chromosomes accurately. Schneider's aceto-carmine proved to be useful in determining the character of new male material.

\section{RESULTS OF INVESTIGATION:}

The Rose Aphids.

On the roses of this section, both out of doors and in the greenhouse, one commonly finds a brown and a green aphid; and on the various hardy roses there appear in autumn winged mothers of another species with large broods of white or yellowish winter-egg layers, and a little later the winged males are present. The host from which this latter species migrates to the rose for sexual reproduction has not yet been discovered, and the parthenogenetic forms have, therefore, not been studied; it is, however, hoped that these may be obtained in the spring from eggs laid on isolated rose plants in the greenhouse.

In my last year's paper (Stevens, '05) the behavior of the female germ cells, both parthenogenetic and sexual, of the brown rose aphid was quite fully described ('o5, pls. I-III, figs. I-27), but males were not found. This year some males were obtained, but they were very few compared with the number of sexual females, and for some reason the material did not fix so well as that from most of the other species. A few good drawings of the first spermatocyte were made from acetocarmine preparations of the testes taken from specimens collected on November I3 (pl. I, figs. I-3). The metaphase of the second spermatocyte, from a section, is shown in figure 4 . Figure 5 , the metaphase of a segmentation spindle, and figure 6 , the maturation mitosis of the parthenogenetic egg, confirm the results recorded in my earlier paper, showing the double series of maternal and paternal chromosomes in the parthenogenetic generation. No favorable maturation stages of the winter eggs were obtained. The scarcity of males was accounted for by the discovery of male and female embryos in the same individual, but only one or two males to many females. In this species the parthenogenetic females and the males are a reddish brown, while the sexual females are red and the eggs when first laid are green. The males are winged, the sexual females and the mothers of the sexual generations apterous. 
The green rose aphid was studied last year only in the parthenogenetic form and the winter egg, and as there was some doubt as to the number of chromosomes, it did not appear in the published results. As in the case of the brown rose aphid, males are scarce, but some drawings were obtained from aceto-carmine preparations and from a few good sections. The number of chromosomes, seven in the spermatocyte (figs. 7-9, I I I 3, I4), shows this to be a distinct species, as had been indicated by experiments with the two kinds in the greenhouse. All of the forms of this aphid are green, and the freshly laid eggs are colorless.

Figures 7 to 9, drawn from aceto-carmine preparations on November I4: show the equatorial plate of the first spermatocyte. The amount of chromatin may not vary greatly from that in the corresponding cells of the brown aphid, but it is differently distributed. Figure ro is a prophase of the first spermatocyte mitosis showing the side to side pairing of homologous chromosomes. Figure II is a metaphase of the first spermatocyte from a section, and figure 12 a late anaphase showing the lagging pair of chromosomes-characteristic of the first spermatocyte spindle in all of the species studied. Figures $\mathrm{I}_{3}$ and $\mathrm{I}_{4}$ are equatoria: plates of the second spermatocyte, showing the same number and proportionate size of chromosomes as in the first spermatocyte. In figure 15 is shown the double series of 14 chromosomes in a two-cell stage of the parthenogenetic egg. This is also seen in figures $\mathrm{I} 6 a$ and $\mathrm{r} 6 b$, two sections of the germinal vesicle of a parthenogenetic egg nearly ready for maturation. At this stage, as also in the prophase of segmentation mitoses, the chromosomes are larger and more irregular in outline than in the equatorial plate of the spindle.

The third, or migratory rose aphid, has so far yielded no results except from the winter eggs, which have been laid in considerable numbers on isolated rose bushes in the greenhouse. Only one polar spindle was found and that was cut diagonally. The nine chromosomes are shown in figures $i 7 a$ and $I 7 b$; these, however, together with figures 18 and 19 , equatorial plates of segmentation spindles of the winter egg, show the number and size relations of the chromosomes. The two broader and much longer chromosomes are without doubt homologous paternal and maternal elements, and the sixteen shorter ones can easily be paired.

Thus it appears that these three species of rose aphids are as distinctly separated by differences in number, form, and size of chromosomes (figs. 5, I 5, I 8 ) as they are by differences in external characteristics of form, size, and color. 
The Willow Aphids.

In some material collected by Prof. Morgan from willow trees at Saranac, New York, early in September, were found a few young males and mothers of the sexual generation. Figures $20 a$ and $20 b$ are two sections of a first spermatocyte before the pairing of the chromosomes, each section containing one complete series of five. Figure $2 \mathrm{I}$ is a similar stage showing the two largest chromosomes and five of the smaller ones. Figure 22 shows two pairs of homologous chromosomes from a slightly later stage than that of figures 20 and 21 . Figure 23 is the metaphase of the first spermatocyte, and figure 24 shows daughter plates of the anaphase. In figure 25 is seen a pair of second spermatocytes immediately after the formation of the nuclear membrane. The second division was not found, but a drawing of the young spermatid is given in figure 26. The number of chromosomes here is the same as in the brown rose aphid, but the proportionate size is somewhat different. There is more difference in size between the largest and the second in size, and the two smallest are proportionately larger than the corresponding ones in the rose aphid. The mothers of the sexual generations produce offspring of both sexes.

Much to my surprise, material collected on June 29 at Harpswell, Maine, contained sexual forms. These aphids were taken from the hairy, reddish young shoots of one of the dwarf willows, and they could not have been many generations away from the winter egg, for it was still early spring on the coast of Maine. There were a few young males and females, and the apterous parthenogenetic mothers contained embryos in the following combinations :

I. All parthenogetic.

2. All sexual female.

3. Parthenogenetic and sexual female.

4. Parthenogenetic male.

5. Parthenogenetic male and female.

Kyber (1815) mentions finding sexual forms on the willow the last of June, but attributes their presence to the change in sap conditions of the host at the close of the growing season, while in this case they were found on young growing shoots.

The polar spindle of the parthenogenetic egg in metaphase is shown in figure 27 , and prophases of segmentation spindles in figures 28 and 29. Six chromosomes, which evidently form three pairs, are present. Figure 30 shows resting cells of a segmenting parthenogenetic egg. The conspicuous nucleolus with its several vacuoles divides into two as a prophase of nuclear and cell divisions. Figures 31 and 32 are first spermatocytes in metaphase and figures 33 and 34 in anaphase; 
here the smaller chromosome appears always to be the one to lag behind. Figure 35 shows the partial resting stage between the two spermatocyte mitoses. No second spermatocytes were found in division. The same side to side pairing of chromosomes as in the other species was observed.

This species has the smallest number of chromosomes of any of those studied, and it apparently has the smallest amount of chromatin, if we may judge by comparison of the metaphase of the first spermatocyte in the various species.

\section{The Oenothera Aphids.}

As the spermatogenesis of Aphis oenotherae was fully described last year (Stevens '05, p1. IV, figs. 28-42), only two new figures of the first and second spermatocyte will be introduced for comparison with other species having the same number of chromosomes (figs. 36 and 37.) The size relation resembles quite closely that of the brown rose aphid, with which it was compared in my former paper, but the largest chromosome is usually more elongated and the difference between the two largest is greater. (Compare figs. 3 and 36.) In external appearance $A$ phis oenotherae is very different from $A$ phis rosae. The females are a bright red and the males and their apterous mothers green. This aphid was not found on the young plants at Bryn Mawr in spring, or on the Oenotheras at Harpswell, Maine, or Woods Hole, Massachusetts, during the summer. It may therefore have a second host,* from which it migrates to Oenothera biennis in the late summer or autumn.

Another smaller, green aphid was found in abundance on the foliage of the Oenotheras at Harpswell, Woods Hole, and Bryn Mawr. The parthenogenetic form of this aphid is light green, the winter egg-layers darker with a blackish longitudinal stripe on the back, and the apterous males brownish and very small. This was the only species in which apterous males were observed. The equatorial plate of the maturation spindles of the parthenogenetic egg, with eight chromosomes, is shown in figure 38 , the metaphase of the first spermatocyte in figures 39 and 40 , the anaphase in figures $4 \mathrm{I}$ and 42 , and a spermatid in figure 43 .

* Aphis oenotherae has recently hatched in considerable numbers on rosettes of Oenother $x$ biennis, where the eggs were laid in the greenhouse in October. The egg layers were red, but their offspring are both red and green, and individuals of either color, isolated, have produced offspring of the same color in the second and third generations. If they continue to breed true to color an attempt will be made to keep several lines of each color isolated until the sexual generation appears in the autumn. 
The Milkweed Aphids.

On the milkweeds at Woods Hole, only one kind of aphid was found, a very dark colored one-nearly black-which lived in herds attended by ants. Sexual forms were collected on September 27. The metaphase of the maturation mitosis of the parthenogenetic egg is shown in figure 44, and that of a spindle of the 4-cell stage in figure 45. The prophase of a spermatogonial mitosis appears in figure 46 , exhibiting the same double series of chromosomes as in the parthenogenetic egg. The metaphase of the first spermatocyte is shown in figure 47 , and daughter plates of the anaphase in figure 48 . The lagging chromosome in the anaphase (fig. 49) is here the smallest of the four. Figures 50 and $5 \mathrm{I}$ show different views of the anaphase of the second spermatocyte. The number of chromosomes is the same as in the second Oenothera aphid, but the difference in form and size is evident. (Compare figs. 38 and 44, 39 and 47.)

On the milkweeds at Bryn Mawr two species were found in abundance, one pale (white with some brown spots), and the other a brilliant orange. The latter remained parthenogenetic until the plants were destroyed by frosts, no sexual forms appearing. A few drawings were made from the parthenogenetic egg. Figures 52 and 53 are the metaphase of the maturation spindle, with two chromosomes conspicuously larger than the other six. Figure 54 is a similar stage, but the two largest chromosomes are evidently united. Two equatorial plates of this kind were found in embryos of one mother, while the usual number-eight-appeared in segmentation stages of eggs in the same embryos. In this species the chromosomes become distinct and take stains well from the moment when the growth stage of the oöcyte begins. A young oöcyte, just leaving the ovary, is shown in figure 55. A large plasmosome $(p)$ and six of the chromosomes appear in this section. A prophase of mitosis in a r6-cell stage is shown in figure 56 , and a section of a 4-cell stage, showing the polar body $(p b)$ and the metaphase of three spindles, in figure 57 .

In the spermatocytes of the pale milkweed aphid there are seven chromosomes, always grouped in a characteristic way (figs. $5^{8}$ and 59). The smallest chromosome is closely associated with the next in size and the two occupy the center of the plate. The arrangement suggested the conditions in some of the Hemiptera heteroptera, but careful examination of the anaphase of both maturation spindles showed that these two chromosomes divide like the others, both, however, lagging behind the others (figs. 60 and 61 ). Figure 62 is a 
daughter plate of the first spermatocyte. Figures $6_{3}$ and $6_{4}$ are slightly different stages in the pairing of the chromosomes as a prophase of the first maturation mitosis. In the second spermatocyte the two smallest chromosomes are as widely separated as any other two (fig. 65). One individual in this material had nine instead of seven chromosomes in the spermatocytes, the two smallest closely associated in the center of the plate and seven in the outer circle. This was probably a stray specimen of another species, perhaps closely related, for here the arrangement of the chromosomes seems to be as characteristic of the species as their form and size. One day's collection of this material contained several individuals which, on dissecting, showed both embryos and winter eggs from the same ovaries, thus confirming what I found once among my rose aphids in the greenhouse; but the fact that I coliected and examined a great deal of the same kind of material from the same locality on the following days, and found no more cases of this kind, shows it to be of rare occurrence.

In the black and the orange milkweed aphids we have two conspic. uously different aphids with chromosomes of the same number and not markedly different size relations. A similar looking aphid to the black milkweed aphid was found on the garden nasturtium, and here the number and size of the chromosomes is near enough the same to make it probable that they are the same species. Figures 66,67 , and 68 show the prophase and metaphase of the first spermatocyte of the nasturtium aphid.

\section{The Oak Aphids.}

On the red oak were found some peculiarly marked red and yellow aphids, the males having spotted wings. These have seven chromosomes in the spermatocytes (fig. 69). Figure 70 is a daughter plate of a first spermatocyte, figure $7 \mathrm{I}$ an equatorial plate, and figure 72 a daughter plate of a second spermatocyte. One specimen in this material had eight chromosomes, the arrangement being similar to that in the pale milkweed aphids, but the number different (figs. 73 and 74$)$.

On another species of oak was found a white aphid with seven chromosomes, varying considerably in size from those of the red oak aphid. First spermatocytes are shown in figures 75 to 78 . These figures show no uniformity of grouping. In fact, the only point of uniformity so far discovered in any species is the close association of the same two chromosomes in the first spermatocytes of the pale milkweed aphids and the one stray red oak aphid (figs. 58 and 73). 


\section{The Goldenrod Aphids.}

The goldenrods, besides serving as hosts for several beetles, offer to the insect collector at least two distinct species of aphids. On the beach goldenrod are large numbers of dark brown aphids with green males. The sexual forms were found at $\mathrm{W}^{\top}$ oods Hole on September 27. The polar body $(p b)$ and the segmentation nucleus of the parthenogenetic egg are shown in figures $79 a$ and $79 b$, the metaphase of the first spermatocyte in figures 80 and $8 \mathrm{r}$, one daughter plate of a late anaphase in figure 82 , the metaphase of the second spermatocyte in figure 83 , and one of the daughter plates of an anaphase in figure 84. In this species four of the chromosomes are of nearly the same form and size, the other two being very much smaller and one slightly smaller than the other. This was the first aphid in which both male and female embryos were found in sections of the same individual: This was quite unexpected, as in the forms studied last year, particularly the Oenothera aphid and the migratory rose aphid, the male and female sexual generations seemed to be entirely separate, the former from apterous, the latter from winged mothers.

The tall goldenrod, Solidago altissima, is the host of quite a different aphid with the same number of chromosomes. The ordinary parthenogenetic individuals and the sexual females are green, the males red, and the mothers of the sexual generation either green or red, individuals of both colors giving rise to both male and female progeny. Figures 85 and 86 are prophases of the first spermatocyte mitosis, figure 85 before the pairing of the chromosome and figure 86 during that process. Figure 87 is the metaphase and figure 88 an early anaphase of the first spermatocyte from material fixed with Gilson's fluid, figures 89 and 90 from Flemming material. Figures 9 I and 92 are the metaphase of the second spermatocyte. The chromosomes, though the same in number, will be seen to differ considerably from those of the brown goldenrod aphid in both form and size.

The Clover, Birch, and Beech Aphids.

On the paper birch were found the sexual forms of a brown aphid. Most of the males were too old to be of use and there were no parthenogenetic forms when they were discovered late in October. Only one drawing of the first spermatocyte, showing nine chromosomes, was made from an aceto-carmine preparation (fig. 93). Only a few young males of the clover aphid were obtained. The testes of these showed a characteristic metaphase of the first spermatocyte containing one large chromosome surrounded by a circle of seven nearly 
equal in size (fig. 94). Figures 95 and 96 are prophases of the first maturation mitosis.

The first and second spermatocytes of the woolly beech aphid have such equatorial plates as are seen in figures 97,98 , and 99. The anaphase (figs. roo and IOI) is rather interesting, as here the lagging chromosome is evidently the largest.

\section{The Star Cucumber Aphid.}

This aphid was discovered quite late, just before the frost killed the host plant, and only the sexual generation with the mothers of the males and females was present. The males were winged and red, the females pale green, and the mothers of the sexual generation were, some red, others bright green. Here again the same mother gives rise to both sexes.

Some of this material was fixed in Hermann's fluid, and figures I 02 to I05 were taken from the Hermann material. This fixation was no better for the mitotic phases than that obtained with the Gilson formula, but the nuclei of the young spermatocytes showed more definite structure (figs. IO2 and I03). The plasmosome did not take the hæmatoxylin stain, but remained a yellowish gray, while the chromatin appeared in a variously tangled and wound feathery spireme. Figure 106 also shows the metaphase of the first spermatocyte and figure 107 an early anaphase. Figure ro4 is a prophase showing the paired condition of one of the longer chromosomes, and figures ro8 and 109 are pairs of daughter plates from the second spermatocyte. In this aphid we have a marked difference in the size relation of the chromosomes from that in the other species that have the same number. (Compare figs. $3,23,36$, 105 or 106).

\section{The Maple Aphid.}

This is a pale aphid-white with some brown markings. Its chief peculiarity consists in the large number of chromosomes-sixteen in the spermatocytes. As shown in figure IIO, one chromosome is a1ways much larger than the rest, and the other fifteen vary only slightly in size. There are often two lagging chromosomes (fig. I I I) in the anaphase of the first spermatocyte, and one daughter plate is usually concentrated before the other, giving the unsymmetrical appearance of figure II2. In figure II3, a prophase of the first spermatocyte mitosis, paired chromosomes are shown. The parthenogenetic forms were not examined. 
The Pea Aphid.

The pea aphid, or pea louse, as it is commonly called, shows a very neatly paired double series of eight chromosomes in the parthenogenetic generations. Figure $\mathrm{Ir} 4$ is from a maturation spindle and figures I 5 and II 6 from a 32 -cell stage of the parthenogenetic egg. The sexual forms were not available for study.

The Goumi Aphid.

On the shrub known as the goumi is found an interesting aphid of which I discovered the sexual forms too late to get anything of the spermatogenesis or to find the parthenogenetic forms. The males were small and nearly black; the females of three distinct colorsgreen, red, and yellow - but all were marked alike with a darker stripe on the back. When brought into the laboratory they laid their orange-colored eggs in abundance on a white cloth tied over the jar in which they were confined to prevent their traveling all over the laboratory.

Figures II 7 and II 8 show polar bodies containing five chromosomes, and figure II the male and female pronuclei in contact, the female nucleus being the larger and containing two plasmosomes $(p)$.

Figures I $20 a$ and $\mathrm{r} 20 b$ show a prophase of mitosis from an 8-cell stage. Such stages are of course not so good for comparison of the chromosomes as the equatorial plate, but the two series of homologous chromosomes are fairly well shown, considering that they do not all lie in the same plane or even exactly parallel with the surface of the section.

In many cases more stages might have been figured, but it did not seem advisable to multiply figures more than was necessary to show the characteristic appearance and behavior of the chromosomes of each species. Several drawings of the same stage have often been given to show the variations in arrangement of the chromosomes. 


\section{SUMMARY OF RESULTS.}

1. Each species of aphids is characterized not only by a specific number of chromosomes, but by peculiarities in their form and size, and in some cases by a definite arrangement, as in the clover aphid, the pale milkweed aphids, and the second oak aphid described (figs. $58,59,73,74,94)$. Where the number of chromosomes is the same in two species, there is always some characteristic difference in form or size corresponding to the external differences in the species.

2. No evidence of hybridism has been observed where two or more species occur on the same host.

3. There is no evidence of any reduction in the number of chromosomes, or of more than one maturation mitosis in the parthenogenetic generations.

4. A double series of homologous paternal and maternal chromosomes runs through the parthenogenetic generations, and the homologous chromosomes are paired side to side in the first spermatocyte, and presumably in the oöcyte, of the sexual generation (figs. ro, 22, $63,64,68,86$, ro4, I I 3 ).

5. The first spermatocyte mitosis is the reducing division, separating homologous chromosomes paired during the prophase.

6. There are no heterochromosomes of any kind, but the spermatids are all alike so far as number, form, and size of chromosomes is considered.

7. The same parthenogenetic individual may produce:

(I) All parthenogenetic embryos.

(2) Parthenogenetic embryos and winter eggs.

(3) All sexual female embryos.

(4) All male embryos.

(5) Parthenogenetic and sexual female embryos.

(6) Parthenogenetic and male embryos.

(7) Parthenogenetic, male, and sexual female embryos.

(8) Male and sexual female embryos. 


\section{GENERAL DISCUSSION.}

\section{The Relation of Species.}

If we may suppose that all the species of aphids having the same number of chromosomes have come from the same ancestors, the mutations may be indicated by such differences in the form and size relations of the chromosomes as may, be seen by comparing the first spermatocyte of the brown rose aphid, the Saranac willow aphid, the Oenothera aphid, No. I, and the star cucumber aphid, with five chromosomes (figs. 3, 23, 36, I05); or that of the black milkweed aphid, the Oenothera aphid No. II, and the nasturtium aphid with four chromosomes (figs. 39, 47,66); or again, the metaphase of the maturation spindle of the parthenogenetic egg of the orange milkweed aphid and the pea aphid with eight chromosomes for the somatic number (figs. 52, I I4). It is evident that mutations might as easily occur by a change involving the number of chromosomes as their form and size.

The three species having the two smallest chromosomes closely associated in the metaphase of the first spermatocyte (figs. $5^{8}$ and 73), but differing in the number of chromosomes-seven, eight, and ninewere similarly marked and probably closely related.

The five species having five chromosomes for the reduced number were obviously different in form, size, and color, while of those having four chromosomes in the spermatocytes only the black milkweed aphid and the nasturtium aphid were nearly enough alike to suggest that they might be the same species, though one was found on milkweed at Woods Hole, Massachusetts, and the other on garden nasturtiums at Bryn Mawr, Pennsylvania.

The two oak aphids, where the number and size relations of the chromosomes are similar (figs. 69 and 76 ), were very unlike in appearance when collected, one being red and yellow, the other nearly white with some brown dots ; but the alcoholic specimens, minus their coloring, were strikingly alike.

The two goldenrod aphids, with the same number of chromosomes but somewhat different form and size relations (figs. 80 and 87), are extremely unlike in appearance, one being a dark reddish brown with green males, the other green with bright red males.

This examination of a few out of the hundreds of species of aphids has indicated to me that an intelligent classification of these insects can be hoped for only when a careful study of the external characters and habits of the various species is combined with an equally careful study and comparison of their germ cells. My work can be regarded as at present the smallest beginning of such a study, and is merely 
suggestive of what may be necessary in the way of a combination of systematic with cytological methods.

\section{Mendel's Law and the Individuality of the Chromosomes.}

It would hardly be possible to find better material than the germ cells of the aphids to illustrate the individuality of the chromosomes, and the probable working of Mendel's Law of Heredity.

In every one of the twenty-four species examined some or all of the chromosomes possess characteristics which distinguish them from their fellows, and these peculiarities persist throughout all the generations. In every species where it has been possible to study and compare the germ cells of the parthenogenetic and sexual generations, the single series of the maturating sexual germ cells has been found to be exactly duplicated in the double series of the parthenogenetic egg, the segmenting winter egg, and the spermatocytes before reduction; and there seems to be no room for doubt that homologous maternal and paternal chromosomes are paired and then separated in maturation.

That the spermatids must be "pure" with regard to the paternal and maternal characters represented by the several pairs of chromosomes is indicated by the fact that in the spermatocyte pairing of the chromosomes does not occur until the prophase of the first maturation mitosis, and even then the homologous chromosomes are merely paired without close union. There is therefore little opportunity for mingling of the chromatin elements of any two paired chromosomes.

In such a case as that of the Harpswell willow aphid with only three chromosomes in the spermatocyte there must be extreme correlation of characters, as only six different combinations of maternal and paternal chromosomes would be possible in the mature eggs and the spermatozoa, while in the maple aphid with sixteen chromosomes, a large variety of different combinations of maternal and paternal characters is possible. Why there should be so marked a difference in number of chromosomes and in amount of chromatin in the several species is at present inexplicable. I thought at first that it might be possible to homologize the various series, and see where a single chromosome in one species might be equivalent to two or more in another, the amount of chromatin being approximately the same in all. A comparative glance at the plates is enough to show that such an attempt would be futile. The difference in amount of chromatin in the same stage of maturation-for example, the metaphase of the first spermatocyte, in material treated in exactly the same waythough not so great as the difference in number, is still very evident. 


\section{SEX DETERMINATION.}

Though this study was undertaken with the hope that it, together with experimental work, might throw considerable light on the much discussed question of sex determination, it has yielded more abundant results along other lines.

The discovery of embryos and winter eggs in the same parthenogenetic individual has been confirmed, but shown to be of rare occurrence. However, the fact that this can occur is evidence that the parthenogenetic and winter eggs are different in method of development, rather than in their original constitution.

Several new points as to the relation of the sexual to the parthenogenetic generations have been gained (Summary of Results, No. 7). It will be seen at once that these relations are such as to prove conclusively that the changes in sex usually attributed to changes in external conditions are really a change from the parthenogenetic to the sexual mode of reproduction. This point has been fully discussed by Castle in his paper on the Heredity of Sex, page I9o ('o3). It might still be maintained that different external conditions had caused some eggs to develop into male and others into female embryos in the same individual, had not embryos been repeatedly found of different sexes and of exactly the same size, and presumably of too near the same age to make it probable that the developing eggs had been given their sex impulse by different external conditions. Careful examination was made to see whether, in cases where embryos of both sexes occurred, all from one ovary were of the same sex, and also whether, if both sexes come from the same ovary, there is any definite order of succession in the oviducts. These are not easy questions to answer from sections which cut the embryos in various planes, but it was ascertained that both sexes occur in the same oviduct, and that embryos of different sexes may alternate or two or more successive embryos may be of the same sex.

From the results recently obtained in the study of the germ cells of other insects [McClung ('99-'05), Sutton ('02, 'O3), Wilson ('o5) Stevens ('o5) ], it now seems probable that the sex character is represented in the chromatin in the germ cells and behaves like other Mendelian characters, as suggested by Castle ('o3). Assuming that this is true, the spermatozoa must be dimorphic with respect to the sex character-one half of them containing the male character, the other half the female character-since the mothers of the males may produce both male and female offspring, and there is no reduction of chromosomes in the eggs which develop into male embryos. 
It is evident that every fertilized aphid egg must contain the female sex character, since it invariably produces a parthenogenetic female. The possible combinations of parthenogenetic, sexual female, and male embryos cited in No. 7 of the Summary of Results, page I3, show that in all probability every parthenogenetic female is capable of producing sexual female progeny; in other words, the female character is dimorphic, if one may so describe it. It gives rise under some conditions to the development of a parthenogenetic female, under other conditions to a sexual female. Now it remains to be determined whether ( $\mathrm{I}$ ) each fertilized egg also contains the male character recessive (Castle, '03), or (2) whether only a part of the eggs contain the male and female characters as alternates, while the remainder have the female character in both the maternal and paternal series of chromosomes. The former condition-male and female characters in all eggs-would imply maturation of the winter eggs according to the law of chances and meeting in fertilization of only eggs and spermatozoa containing different sex characters (Castle, '03). The latter condition might be the result of such a differential maturation of the eggs that all should contain only the female sex character before fertilization. The sex possibilities of the fertilized egg would then be determined by the entrance either of a spermatozoön containing the male character or of one containing the female character. An egg fertilized by a spermatozoön containing the female character would then produce a line of aphids consisting only of parthenogenetic females and sexual females. An egg fertilized by a spermatozoön containing the male element would be capable of producing a succession of generations consisting of parthenogenetic females, sexual females and males. This is just what we find (Summary, No. 7), but the same conditions could occur if all the fertilized eggs contain both male and female characters.

The fact that in some species (Oenothera aphid No. I and the white rose aphid) the two sexes are entirely separate in the sexual generation, and that in the six species in which embryos of both sexes are found together there are always many individuals that contain only female embryos, suggested the possibility that there might be in each species entirely separate lines from the fertilized egg through the parthenogenetic generations to the sexual generation, some lines being capable of producing males, others not. The only way to test this point would be to isolate parthenogenetic individuals of a species, either directly from the fertilized egg or from somewhat widely separated hosts, and examine the sexual generations from each. If many individuals from some lines of descent should give only sexual 
females, while those from other lines gave either only males or both males and females, the natural conclusion would be that some fertilized eggs contain the male character, while others do not. If, on the other hand, both males and females should occur in all the lines of descent, we should feel reasonably sure that all the fertilized eggs contain both the male and female character.

Unfortunately there is no such visible dimorphism in the spermatids of the aphid as in some of the Hemiptera, Orthoptera, and Coleoptera to serve as direct evidence of sex-determining power, but if the sex characters are represented in the chromatin as Mendelian alternates there is abundant evidence that the spermatogonia must contain both characters and that the spermatozoa must be pure as to the two alternating characters.

As to which seems the more likely supposition (I) that only germ cells with opposite sex characters can unite to give a fertile egg, or (2) that all the winter eggs can be so maturated that only the female character remains, one proposition seems about as likely to be true as the other; and at present I see no third possibility, since there is no evidence that the female element is removed from the parthenogenetic eggs that produce males (Castle,'o3) and the spermatozoa must therefore be of two kinds respecting the sex characters, just as in the case of any other two homologous maternal and paternal characters.*

Whatever evidence isolation experiments may give on this point of the distribution of the male and female characters in the fertilized egg, we know that from one parthenogenetic egg can come an individual whose germ cells can produce (r) parthenogenetic, (2) sexual female, or (3) male offspring, and so far as we can see the indications are that the same influences that cause a change in the mode of reproduction from parthenogenetic to sexual produce in some species or in some individuals of a species a definite change in dominance of the sex characters (Oenothera aphid No. I and white rose aphid), while in other species (goldenrod and willow aphids) a more or less balanced state of dominance must be associated with the initiation of sexual

* In the case of Aphis oenotherae it is possible that the germ cells of the red parthenogenetic individuals contain the female sex character in both the paternal and the maternal series of chromosomes, while the green individuals have the female sex character in the maternal series and the male in the paternal series, the green color being correlated with the male sex character and dominating over the maternal red. The former line would then give rise to sexual females and winter eggs containing only the female character; the latter, by a change in dominance of the sex character, would produce males containing both characters. Fertilization by the resulting two classes of spermatozoa would then perpetuate the two sexual lines. 
reproduction and some unknown internal factor determine which sex character shall control the development of each egg. The whole question of sex determination will be seen to be far more complex in the case of the aphids than in insects where no parthenogenetic generations intervene between the fertilized egg and the production of males.

In collecting aphids this year it was found that the sexual generation appeared in many species from two to three weeks earlier than in I 903 and 1904, though the weather continued warm much later than during the two preceding autumns. This seemed to be related to the earlier ripening up of the various host plants. The earlier fruiting and drying up was especially conspicuous in Oenothera biennis and some of the rose bushes. Sexual forms of both the brown and green rose aphid were found on young growing tips of these same bushes, but they may have been affected by the general sap conditions of the plant. Finding sexual forms among the willow aphids collected from young shoots at Harpswell, Maine, on June 29, suggested that in some species there may be definite cycles of generations not directly subject to external conditions, as Weismann maintains for the Daphnids (' 76, ' 79$)$. This species of aphids deserves further investigation.

One is also somewhat mystified by the fact that in some species there is a sudden and complete change from the parthenogenetic to the sexual mode of reproduction, while in others, as for example the brown and the green rose aphids, parthenogenetic generations continue to multiply until destroyed by the cold of winter. The complete change seems to be the rule in the majority of the species in this climate, and is much more easily explained than the mixed condition.

So far it has not been possible to produce the sexual generations by subjecting the aphids to artificial changes of conditions. This may be due to the fact that the brown and green rose aphids, which have been used for most of the experiments, may be the most unfavorable for such work, as they produce scattered sexual forms while continuing the parthenogenetic generations, indicating either that they are less sensitive to changes in environment or that they are less well adapted to this climate.

This is evidently a case where experimental work must be based on rather extensive observation and cytological research, and the results recorded in this paper give a far better basis for experiment than we had a year ago.

BRYN MAWR COLLEGE, Jamuary 15, 1906. 



\section{BIBLIOGRAPHY.}

Castle, W. E.

'o3. The heredity of sex. Bull. Mus. Comp. Zoöl. Harvard College, vol. 40, no.4. KYBer, J. F.

'r5. Finige Erfahrungen und Bemerkungen über Blattläuse. Germar's Magazin der Entomologie, t. I-2c.

McClung, C. E.

'99 A peculiar nuclear element in the male reproductive cells of insects. Zoöl. Bull., vol. 2.

'oo. The spermatocyte divisions of the Acridiidæ. Kans. Univ. Quart., vol. 9, no. I.

'or. Notes on the accessory chromosomes. Anat. Anz., bd. 20, nos. 8 and 9.

'o2. The accessory chromosome-Sex-determinant? Biol. Bull., vol. 3, nos. I and 2.

'02a. The spermatocyte divisions of the Locustidæ. Kans. Univ. Quart., vol. I, no. 8.

'05. The chrǫmosome complex of orthopteran spermatocytes. Biol. Bull., vol. 9, no. 5 .

Stevens, N. M.

'05. A study of the germ cells of Aphis rosae and Aphis oenotherae. Journ. of Exp. Zoöl., vol. 2, no. 3 .

'05a. Studies in spermatogenesis, with especial reference to the "accessory chromosome". Carnegie Inst. of Wash., pub, no. 36.

Sutron, W. S.

'02. On the morphology of the chromosome group in Brachystola magna. Biol. Bull., vol. 4, no. I.

'03. The chromosomes in heredity. Biol. Bull., vol. 4 , no. 5 .

WeISMANn, A.

'76-79. Beiträge zur Naturgeschichte der Daphnoiden. Leipzig.

Wilson, E. B.

'05. The behavior of the idiochromosomes in Hemiptera. Journ. of Exp. Zoöl., vol. 2, no. 3 .

'05a. Studies on chromosomes. II. The paired microchromosomes, idiochromosomes, and heterotropic chromosomes in Hemiptera. Journ. of Exp. Zoöl., vol. 2 , no. 4 . 


\section{DESCRIPTION OF PLATES.}

[The figures were all drawn with camera lucida, Zeiss oil-immersion $2 \mathrm{~mm}$., oc. 12 and have been reduced one-third, giving a magnification of tooo diameters.]

\section{Plate I.}

\section{Brown rose aphid.}

FIGS. I-3. First spermatocyte, metaphase, aceto-carmine preparation of November I3.

4. Second spermatocyte, metaphase.

5. Parthenogenetic egg, metaphase of segmentation spindle.

6. Parthenogenetic egg, metaphase of maturation spindle. The double series of chromosomes is numbered, here and in other figures, in order of size.

\section{Green rose aphid.}

7-9. First spermatocyte, metaphase, aceto-carmine preparation of November I4.

I0. First spermatocyte, prophase, showing paired chromosomes.

II. First spermatocyte, metaphase, from section.

I2. First spermatocyte, late anaphase.

13-14. Second spermatocyte, metaphase.

I5. Two-cell stage of parthenogenetic egg, metaphase, showing the double series of $\mathrm{I} 4$ somatic chromosomes.

I6 $\alpha$ and $b$. Parthenogenetic egg, prophase of maturation mitosis showing $I_{4}$ chromosomes.

\section{Migratory rose aphid.}

I $a$ and $b$. Winter egg, first maturation mitosis, metaphase, 9 chromosomes. I8-19. Winter egg, metaphase of segmentation spindles, 18 chromosomes.

\section{Saranac willow aphid.}

$20 \alpha$ and $b$. First spermatocyte, prophase, showing double series of ro chromosomes.

2I. First spermatocyte, prophase.

22. Paired chromosomes from prophase of first spermatocyte.

23. First spermatocyte, metaphase.

24. First spermatocyte, anaphase.

25. A pair of second spermatocytes.

26. Young spermatid.

\section{Harpswell willow aphid.}

27. Parthenogenetic egg, metaphase of maturation spindle.

28-29. Parthenogenetic egg, prophases of segmentation mitosis. 

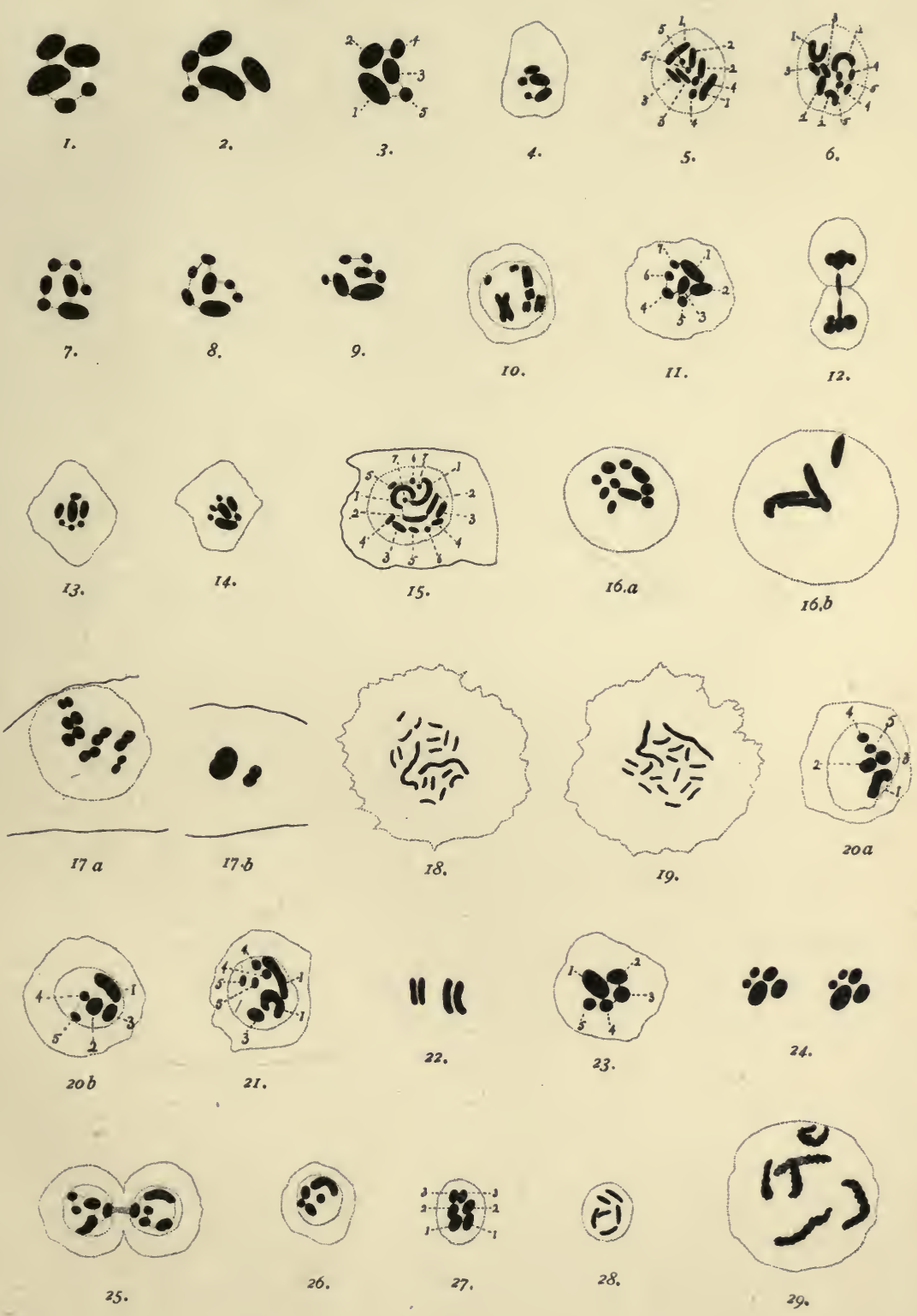

N. M, s. del. 



\section{Plate II.}

\section{Harpswell willow aphid.}

FIG. 30. Parthenogenetic egg, resting nuclei, showing nucleolus divided before mitosis.

3I-32. First spermatocyte, metaphase.

33-34. First spermatocyte, anaphase.

35. Second spermatocyte, prophase.

\section{Aphis oenotherae.}

36. First spermatocyte, metaphase.

37. Second spermatocyte, metaphase.

\section{Oenothera aphid, No. II.}

38. Parthenogenetic egg, metaphase of maturation spindle.

39-40. First spermatocyte, metaphase.

4r. First spermatocyte, early anaphase.

42. First spermatocyte, late anaphase.

43. Young spermatid.

\section{Black milkweed aphid.}

44. Parthenogenetic egg, metaphase of maturation spindle.

45. Parthenogenetic egg, 4-cell stage, metaphase of segmentation spindle.

46. Spermatogonium, prophase of mitosis.

47. First spermatocyte, metaphase.

48-49. First spermatocyte, anaphase.

50-5r. Second spermatocyte, anaphase.

\section{Orange milkweed aphid.}

52-53. Parthenogenetic egg, metaphase of maturation spindle.

54. Parthenogenetic egg, metaphase of maturation spindle, showing the two largest chromosomes united $(\mathrm{I}+\mathrm{r})$.

55. Young oöcyte, showing plasmosome $(p)$ and six of the chromosomes.

56, Parthenogenetic egg, I6-cell stage, prophase of mitosis.

57. Parthenogenetic egg, polar body $(\not . b$.$) and three segmentation spindles.$ 

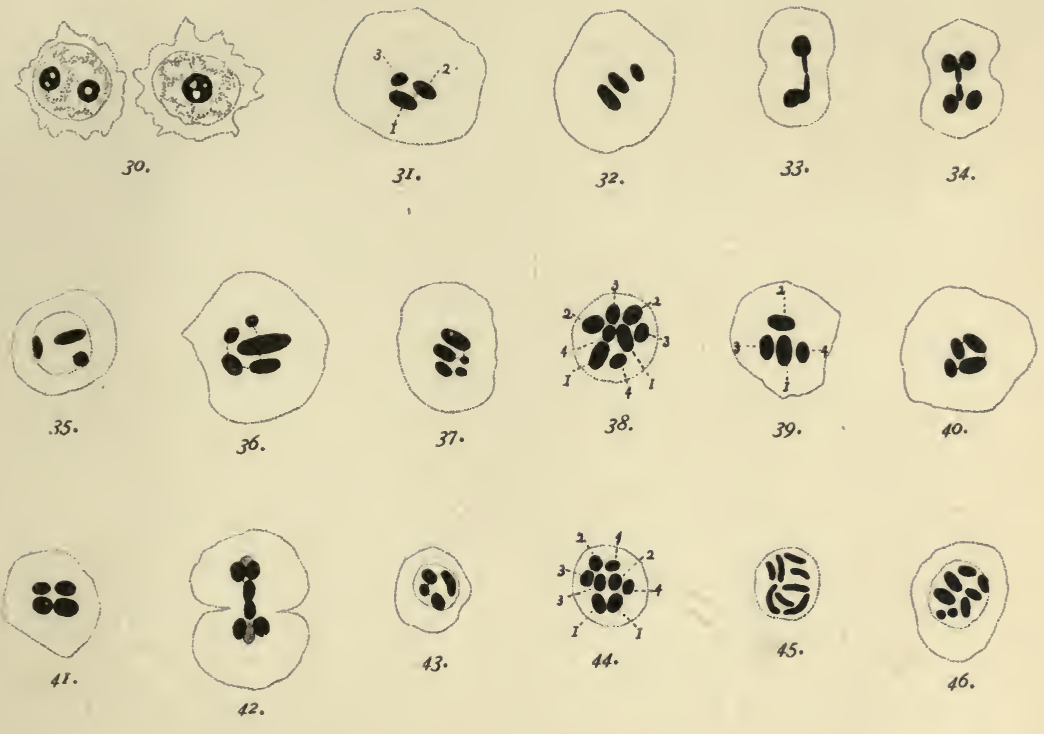
$(00,100$

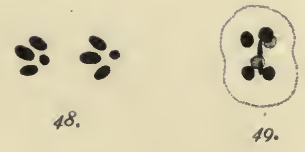
8: ::
50.
0
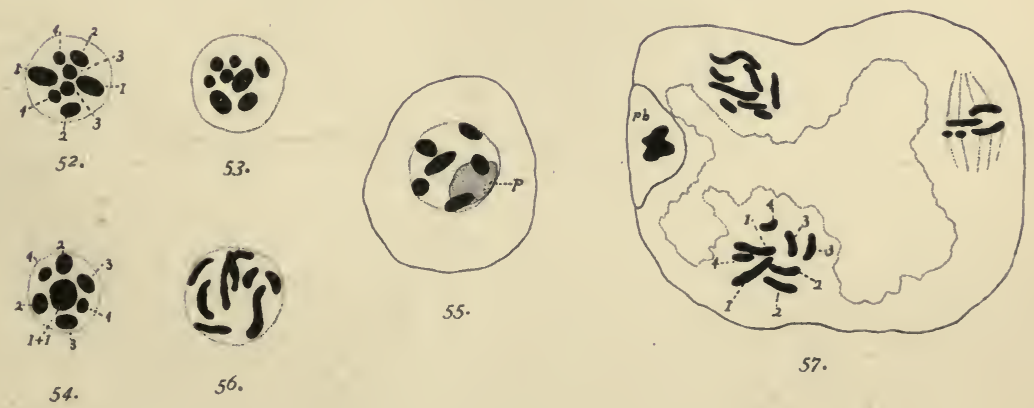

N. M, S. del. 


Plate III.

Pale milkweed aphid,

FIGS. 58-59. First spermatocyte, metaphase.

60-6т. First spermatocyte, anaphase.

62. First spermatocyte, daughter plate.

63-64. First spermatocyte, prophase. showing paired chromosomes.

65. Seccnd spermatocyte, metaphase.

\section{Nasturtium aphid.}

66. First spermatocyte, metaphase.

67-68. First spermatocyte, prophase.

\section{Oak aphids.}

69. No. I, first spermatocyte, metaphase.

70. No. I, first spermatocyte, anaphase.

7I. No. I, second spermatocyte, metaphase.

72. No. I, second spermatocyte, anaphase.

73-74. No. II, first spermatocyte, metaphase.

75-77. No. III, first spermatocyte, metaphase.

78. No. III, first spermatocyte, anaphase.

\section{Beach goldenrod aphid.}

$79 a$ and $b$. Parthenogenetic egg, polar body and prophase of first segmentation mitosis.

80-8r. First spermatocyte, metaphase.

82. First spermatocyte, anaphase,

83. Second spermatocyte, metaphase.

84 , Second spermatocyte, anaphase.

\section{Tall goldenrod aphid.}

85. First spermatocyte, before pairing of chromosomes.

86. First spermatocyte, prophase, showing paired chromosomes.

87. First spermatocyte, metaphase, Gilson.

88. First spermatocyte, early anaphase, Gilson.

89. First spermatocyte, metaphase, Flemming.

9o. First spermatocyte, early anaphase, Flemming.

91-92. Second spermatocyte, metaphase. 

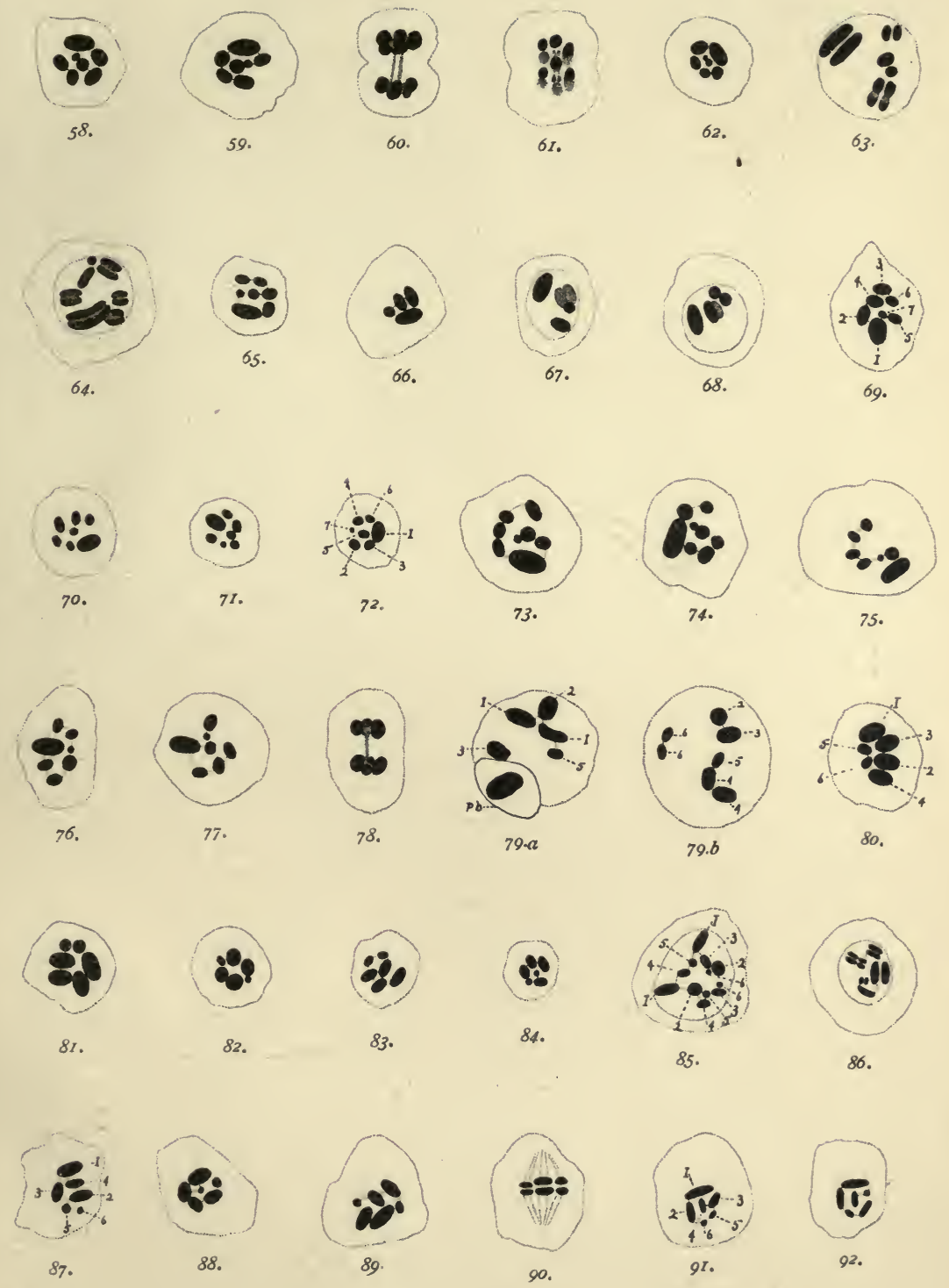

. 
- $\quad$ Plate IV.

Paper birch aphid.

Fig. 93. First spermatocyte, metaphase.

$$
\text { Clover aphid. }
$$

94. First spermatocyte, metaphase. 95-96. First spermatocyte, prophase.

$$
\text { Woolly beech aphid. }
$$

97-98. First spermatocyte, metaphase.

99. Second spermatocyte, metaphase. Iоo-IOI. First spermatocyte, anaphase.

Star cucumber aphid.

r02-I03. First spermatocyte, growth stage.

I04. First spermatocyte, prophase.

I05. First spermatocyte, metaphase, Hermann preparation.

ro6. First spermatocyte, metaphase, Gilson.

I07. First spermatocyte, early anaphase.

ro8 $a$ and $b$. Second spermatocyte, anaphase.

rog. Second spermatocyte, anaphase.

Maple aphid.

IIo. First spermatocyte, metaphase.

III-II2. First spermatocyte, anaphase.

II3. First spermatocyte, prophase.

\section{Pea aphid.}

Ir4. Parthenogenetic egg, metaphase of maturation spindle.

II5-II6. Parthenogenetic egg, 32-cell stage, metaphase of segmentation spindle.

\section{Goumi aphid.}

II 7-II8. Winter egg, polar bodies.

II9. Winter egg, male and female pronuclei.

I20 $\alpha$ and $b$. Winter egg, prophase of segmentation mitosis. 


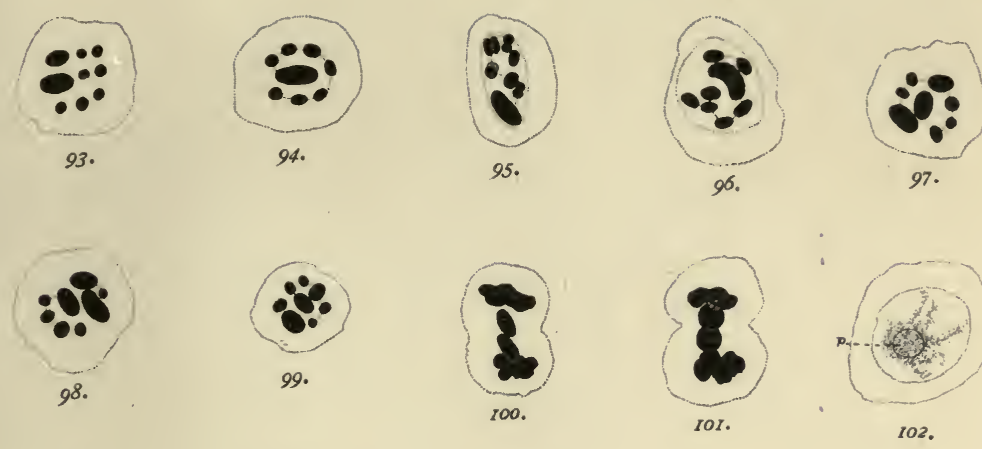

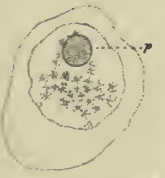

10.3.

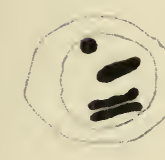

104.

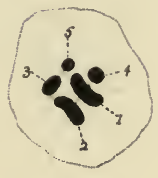

Io5.

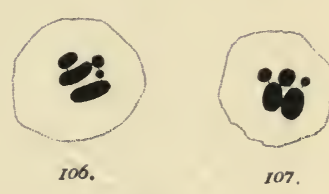

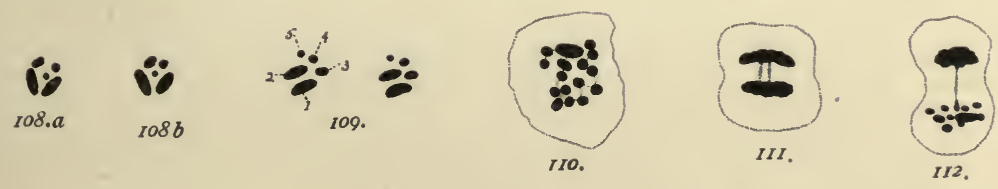
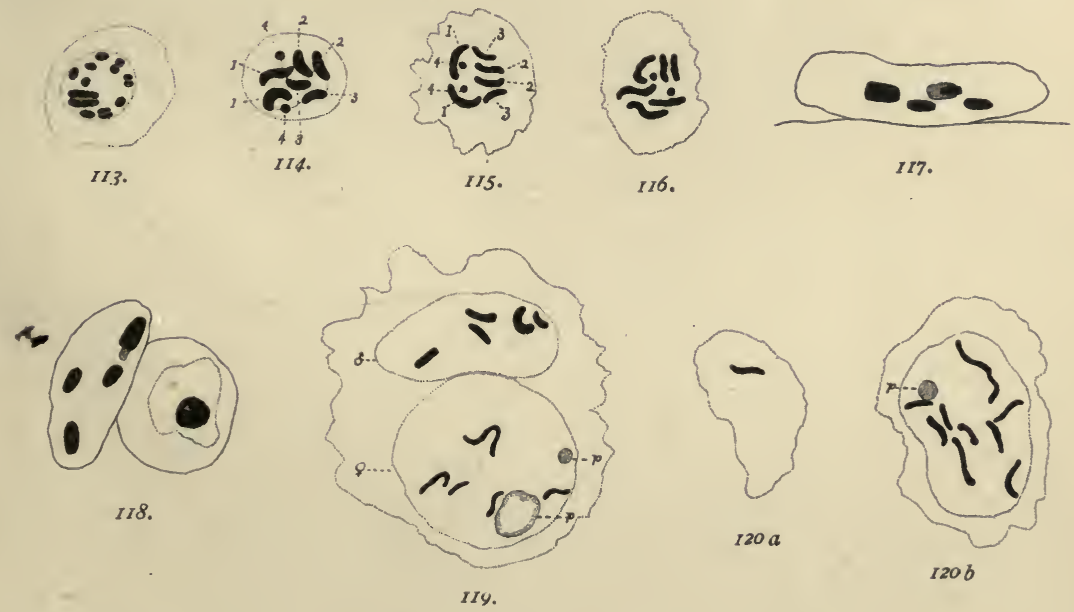

N. M. S. del. 

.

-

4

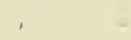

$-1$ 



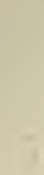

19
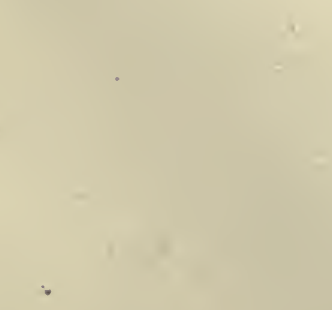

$=$ 

UNIVERSITY OF CALIFORNIA

BRANCH OF THE COLLEGE OF AGRICULTURE

THIS BOOK IS DUE ON THE LAST DATE STAMPED BELOW

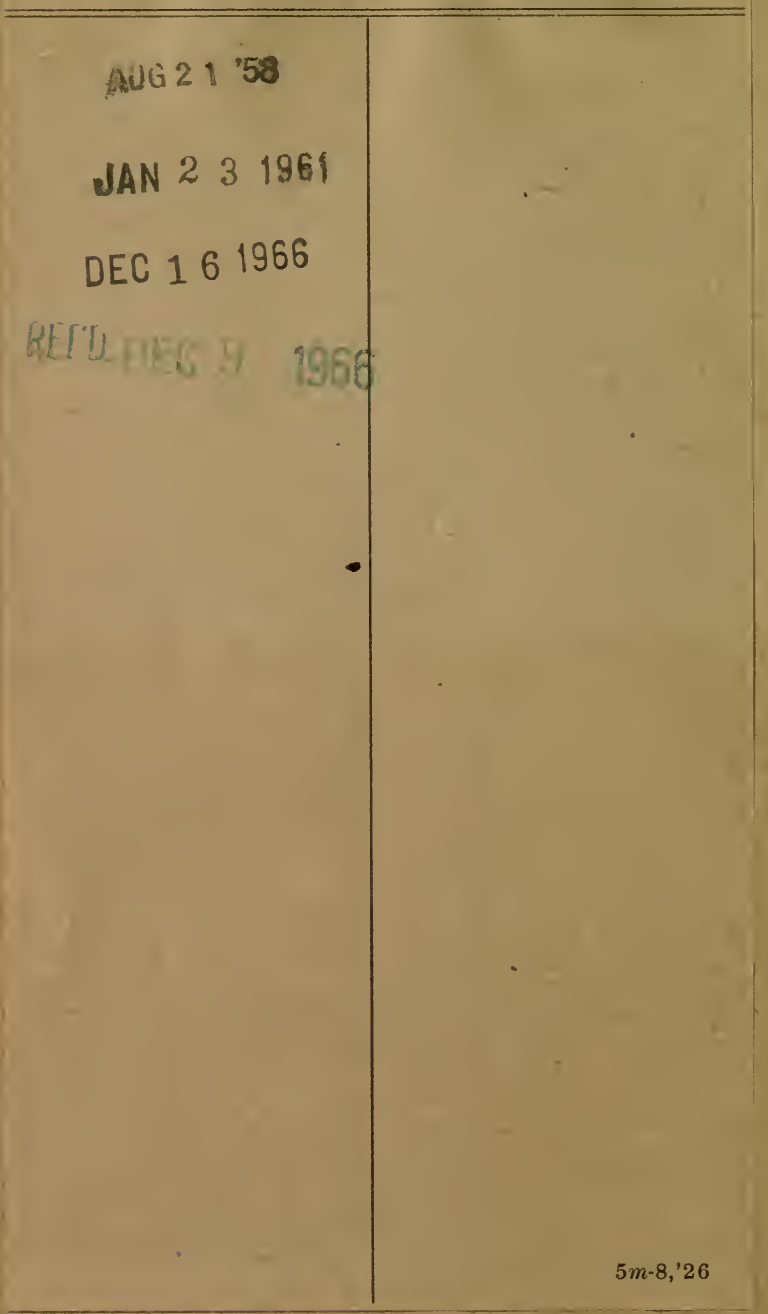


